\title{
Epilepsy due to Neurocysticercosis: Analysis of a Hospital Cohort
}

\section{Marcellin Bugeme ${ }^{1}$, Adjaratou Dieynabou Sow ${ }^{2}$, Olivier Mukuku ${ }^{3 *}$, Athanase Millogo ${ }^{4}$, Oscar Numbi Luboya ${ }^{1,3}$ and Kamadore Touré ${ }^{2}$ \\ ${ }^{1}$ Faculty of Medicine, University of Lubumbashi, Democratic Republic of Congo ${ }^{2}$ Neurological Clinic of the National Teaching Hospital, Université Cheik Anta Diop, Dakar, Senegal ${ }^{3}$ Higher Institute of Medical Techniques, Lubumbashi, Democratic Republic of Congo \\ ${ }^{4}$ Department of Neurology, Souro Sanon University Hospital, Teaching Hospital, Burkina Faso}

\section{Abstract}

Introduction: Neurocysticercosis (NCC) is a common helminthic infection of the nervous system that occurs when humans become intermediate hosts in the life cycle of the pig tapeworm (taenia solium) after ingesting its eggs. The objective of this study was to analyze sociodemographic, clinical and paraclinical features of patients with NCC in Lubumbashi, DRC.

Methods: This is a cross-sectional study conducted over a period of 2 years within the Neuropsychiatric Center of Lubumbashi. Socio-demographic, clinical, paraclinical and therapeutic features were studied.

Results: A total of 18 patients with NCC were listed. Epilepsy was found in $72.2 \%$ (13/18) of the cases. The mean age of the patients was $30.2 \pm 13.5$ years; males accounted for $61.2 \%$ of the cases. $84.6 \%$ were consumers of pork. Generalized epilepsy was found in $84.6 \%$ of the cases and hypereosinophilia in $38 \%$ of the cases. On the neuroimaging, the parietal location of lesions represented $92.3 \%$; calcifications were the type of lesion in $53.8 \%$ of the cases and $69.2 \%$ of the cases presented lesions in the $4^{\text {th }}$ evolutionary stage. Electroencephalogram was normal in $84.4 \%$ of the cases. Phenobarbital was the antiepileptic drug used in $69.3 \%$; albendazole and prednisone were used in $53.9 \%$ of the cases.

Conclusion: This study shows that NCC is one of the causes of epilepsy in Lubumbashi. Generalized tonic-clonic seizures are the most common form of presentation and calcified parenchymal lesions are the most common radiological feature of NCC. So, any patient with acute onset of afebrile seizure should be screened for NCC provided other common causes been ruled out.

\section{More Information}

*Address for Correspondence: Olivier Mukuku, Higher Institute of Medical Techniques, Lubumbashi, Democratic Republic of Congo, Tel: +243997925 649; Email: oliviermukuku@yahoo.fr

Submitted: 28 August 2020

Approved: 23 September 2020

Published: 24 September 2020

How to cite this article: Bugeme M, Sow AD, Mukuku O, Millogo A, Luboya ON, et al. Epilepsy due to Neurocysticercosis: Analysis of a Hospital Cohort. J Neurosci Neurol Disord. 2020; 4: 063-068.

\section{DOI: 10.29328/journal.jnnd.1001036}

Copyright: @ 2020 Bugeme M, et al. This is an open access article distributed under the Creative Commons Attribution License, which permits unrestricted use, distribution, and reproduction in any medium, provided the original work is properly cited.

Keywords: Epilepsy; Neurocysticercosis; Lubumbashi

Abbreviations: AED: Antiepileptic drug; EEG: Electroencephalogram; DRC: Democratic Republic of Congo; NCC: Neurocysticercosis

Check for updates

OPEN ACCESS

\section{Introduction}

Neurocysticercosis (NCC) is a cosmopolitan disease that occurs in developing countries where endemic areas exist [1]. NCC is a common helminthic infection of the nervous system that occurs when humans become intermediate hosts in the life cycle of pig tapeworm Taenia solium, after ingesting its eggs. This disease is most often transmitted by tapeworm carriers to healthy individuals by unhygienic manipulation or by direct contact with human excrement [2]. The ingestion of undercooked pork contaminated with cysticerci is a mistaken belief, because the role of pigs is to maintain the cycle of infection by causing human tapeworm [3]. These eggs release oncospheres which enter the intestinal wall and circulate in the bloodstream to form cysticerci. Cysticerci that form in the brain can cause neurological manifestations, including seizures, headache, intracranial hypertension, encephalitis, cognitive impairment, stroke, focal neurological deficits or even death; which makes NCC a pleomorphic disease [4-7]. These neurological manifestations depend on the number of lesions, their topography, the extent of the inflammatory reaction and the evolutionary stage of the parasite.

Epilepsy is a common neurological condition, especially in developing countries, and can have a devastating effect on people with the disease and their families. The burden of epilepsy in low-income countries is more than twice that of high-income countries, probably because the incidence of risk factors is higher [8]. Among these risk factors, we find the most common infections associated with seizures are NCC, malaria 
and meningitis [8-11]. It is estimated that NCC is responsible for a third of epilepsies in parts of South America [12]. In Lubumbashi (Democratic Republic of Congo), Mukuku, et al. [13] had found NCC as the etiology of epilepsy in $26.5 \%$ of the cases.

A recent study by Del Brutto, et al. [14] demonstrated a strong relationship between epilepsy and NCC in Ecuador in an endemic village for NCC. In sub-Saharan Africa, a study in Tanzania also demonstrated that NCC is a major cause of epilepsy [15].

This study aims to describe socio-demographic, clinical and paraclinical characteristics of patients with an epilepsyNCC association.

\section{Methods}

\section{Study design and setting}

The study took place in the Neuropsychiatric Center of Lubumbashi, located in the southeast of the Democratic Republic of Congo, in the province of Haut-Katanga.

This is a descriptive cross-sectional study of the records of patients with an epilepsy chart related to NCC. This study took place over a 2-year period from January 2015 to December 2016. Our study was carried out on patients admitted for consultation at the Neuropsychiatric Center of Lubumbashi.

\section{Study population}

Our study included all patients admitted for consultation at the Neuropsychiatric Center of Lubumbashi in whom a diagnosis of NCC had been retained by the medical staff according to the diagnostic criteria proposed by Del Brutto, et al. [16].

Epilepsy was defined according to Fisher, et al. [17] by any of the following manifestations:

At least two unprovoked attacks (or reflexes) spaced more than 24 hours apart;

An unprovoked (or reflex) attack and a probability of occurrence of subsequent attacks over the next 10 years similar to the general risk of recurrence (at least 60\%) observed after two unprovoked attacks;

Diagnosis of an epileptic syndrome.

The presence of cysticerci in the CNS (brain) was confirmed by the use of single slice scanner at one tube rotation cCT scan (TOSHIBA CT Scan x-ray machine). The thickness of the slices was $5 \mathrm{~mm}$ at the base of the skull and $10 \mathrm{~mm}$ above the base of the skull. The injection of intravenous contrast agent was not applied in all patients. Images have been digitally archived. CT scan detects ring-enhancing lesions (stage 2) and multiple ring enhancing lesions (stage 3 ) in NCC infected patients.

All images were examined by a neuroradiologist.
Independently, these images were also examined by a specialist neurologist.

\section{Study variables}

The variables studied were as follows: age, sex, eating habit (the question was whether the patient regularly consumed pork), the concept of pig breeding or the pork trade (this involved whether the patient in direct contact with the pig or its meat), place of residence (it was a question of knowing if the patient had had to live near farms), clinical characteristics (type of epileptic seizures), biological characteristics (presence or absence of hyperosinophilia), types of lesions observed in CT scan (corresponding to the evolutionary stages of the cysticercus) and outcome of the patients under treatment started. These lesions have been classified into 4 different types of lesions according to Duchene [18]:

Stage 1: absence of intraparenchymal abnormality visible in CT; the diagnosis of NCC is made by the analysis of the cerebrospinal fluid and by MRI;

Stage 2: CT shows cysts with regular morphology, without inflammatory signs or perilesional edema, sometimes with a hyperdense mural nodule corresponding to scolex;

Stage 3: Intraparenchymentous cysts associated with inflammatory signs due to cystic degeneration, with loss of boundaries, annular or nodular peripheral enhancement or peri-lesional edema;

Stage 4: CT shows a single or multiple nodular, calcified images (residual form).

\section{Statistical analyzes}

Descriptive statistics were used (frequency, average, standard deviation) and the data were analyzed using Epi Info 7.2 software.

\section{Results}

Out of a total of 18 patients in whom NCC was confirmed, $13(72.2 \%)$ presented epileptic seizures. The mean age of the patients was $30.2 \pm 13.5$ years (range: 5 and 50 years). The median was 26 years. The most represented age group was from 20 to 29 years (38.5\% of the cases). We found a predominance of the male sex (61.5\%). Eleven $(84.6 \%)$ patients had direct contact with pigs. The clinical picture was dominated by generalized tonic-clonic seizures $(76.9 \%)$ and secondarily generalized partial seizures (15.4\%). Hypereosinophilia was present in 5 (38\%) patients (Table 1). The electroencephalogram (EEG) was normal in $84.4 \%$ of the cases. Two patients had EEG abnormalities: EEG abnormalities were made of generalized spike and spike discharges in the first patient and the second had spikes in the frontal regions.

The lesions were calcifications in $69.2 \%$ of the cases and the parietal location was the most affected (92.3\%). Six 
(46.2\%) patients had 10 or more lesions (mean number of lesions of $7.83 \pm 4.91)$. Ten $(76.9 \%)$ patients had lesions of a single evolutionary stage. Nine (69.2\%) patients presented lesions in the $4^{\text {th }}$ evolutionary stage (Table 2 ).

Seven (53.8\%) patients received albedanzole as an antiparasitic and corticosteroid treatment. All patients were put on antiepileptic drugs [AED] (phenobarbital was the most used molecule followed by carbamazepine).

\begin{tabular}{|c|c|c|}
\hline Variable & Number $(n=13)$ & Percent \\
\hline \multicolumn{3}{|l|}{ Age } \\
\hline$<20$ years & 2 & 15.4 \\
\hline $20-29$ years & 5 & 38.5 \\
\hline $30-39$ years & 3 & 23.1 \\
\hline$\geq 40$ years & 3 & 23.1 \\
\hline \multicolumn{3}{|l|}{ Sex } \\
\hline Female & 5 & 38.5 \\
\hline Male & 8 & 61.5 \\
\hline \multicolumn{3}{|l|}{ History } \\
\hline Pork consumer & 9 & 69.2 \\
\hline Geophagy & 1 & 7.7 \\
\hline Pork breeder and consumer & 1 & 7.7 \\
\hline Seller and consumer of pork & 1 & 7.7 \\
\hline None & 1 & 7.7 \\
\hline \multicolumn{3}{|l|}{ Type of seizures } \\
\hline Generalized tonic-clonic & 10 & $76 e .9$ \\
\hline Partial secondarily generalized & 2 & 15.4 \\
\hline Myoclonic & 1 & 7.7 \\
\hline \multicolumn{3}{|l|}{ Hypereosinophilia } \\
\hline No & 11 & 84.6 \\
\hline Yes & 2 & 15.4 \\
\hline
\end{tabular}

Table 2: Neuroimaging features.

\begin{tabular}{|c|c|c|}
\hline Variable & Number $(n=13)$ & Percent \\
\hline \multicolumn{3}{|l|}{ Location of lesions } \\
\hline \multicolumn{3}{|l|}{ Intraparenchymal } \\
\hline Frontal & 6 & 46.2 \\
\hline Parietal & 12 & 92.3 \\
\hline Occipital & 5 & 33.5 \\
\hline \multicolumn{3}{|l|}{ Extraparenchymal } \\
\hline Ventricular & 1 & 7.7 \\
\hline Falx cerebri & 1 & 7.7 \\
\hline \multicolumn{3}{|l|}{ Type of lesions } \\
\hline Vesicular cystic lesions & 4 & 30.8 \\
\hline Colloidal cystic lesions & 3 & 23.1 \\
\hline Calcifications & 9 & 69.2 \\
\hline \multicolumn{3}{|l|}{ Number of lesions } \\
\hline 1 & 2 & 15.4 \\
\hline 2 & 1 & 7.7 \\
\hline 3-9 & 4 & 30.8 \\
\hline$\geq 10$ & 6 & 46.2 \\
\hline \multicolumn{3}{|c|}{ Number of evolutionary stages per patient } \\
\hline 1 & 10 & 76.9 \\
\hline$\geq 2$ & 3 & 23.1 \\
\hline \multicolumn{3}{|l|}{ Parasitic evolutionary stage } \\
\hline 2 & 5 & 38.8 \\
\hline 3 & 3 & 23.1 \\
\hline 4 & 9 & 69.2 \\
\hline
\end{tabular}

Stopping seizures was observed in 9 patients after reassessment at 12 months of follow-up and 5 others were evaluated at 6 months of treatment without any reported seizure.

\section{Discussion}

We recorded 18 patients with NCC, of which 13 (72\%) had epileptic seizures. In the DRC (in Kinshasa), Kabeya, et al. found $81 \%$ of epilepsy in patients with NCC [19]. In Nepal, Shrestha, et al. [20] found a frequency of 83\% among patients with NCC; in Bolivia, Miranda, et al. [21] found 66\%. According to the literature review, epilepsy accounts for 50 to $80 \%$ of clinical manifestations linked to NCC [22].

The present study reports an average age of the patients of $30.2 \pm 13.5$ years. In a Burundian study, Nsengiyumva, et al. [23] found an average age of 29.8 years. A Togolese study found an average age of $36 \pm 14$ years [24]. In Ecuador, Brutto, et al. found an average age of $31.9 \pm 17.6$ years [12]. According to data from the literature, cerebral cysticercosis is a zoonosis present at all ages, preferentially affecting adults rather than children [25]. The cumulative effect of exposure with age related to the activities practiced may explain this difference [26].

We found a predominance of the male sex (61.5\%). In Tanzania, in the district of Mbulu, Mwang'onde, et al. [27] also found a male predominance of $60 \%$. The same is true for Millogo, et al. [28] who found a predominance of men in their Burkinabé series. In Ecuador, Brutto, et al. [12], in their study found an equal distribution between men and women.

We noted that $84.6 \%$ of the patients had contact with pigs (consumers, breeders and sellers). Zafindraide, et al. [29] found $96.6 \%$ of consumers of pork, 39\% of whom were breeders. Some studies have shown the link between cysticercal prevalence and the intensity of pig farming [30]. Consumption of pork is important in the transmission of Taenia solium infections. Its prevalence is higher among consumers of pork compared to those who do not eat [29]. In our study, a patient contracted neurocysticercosis through the practice of geophagy. A Senegalese study had shown a large proportion of cysticercosis in children with digestive parasitosis due to geophagy [31]. Geophagy as a mode of contamination of a parasitosis has already been described $[32,33]$.

The clinical picture was dominated by generalized (tonicclonic or myoclonic) and partial seizures, representing 84.6 and $15.4 \%$ respectively. This corroborates an Indian study reporting $82.3 \%$ of generalized seizures and $17.7 \%$ of partial seizures [34]. Several other studies found a predominance of generalized seizures $[28,35]$. Conversely, the studies of Moyano, et al. [36] in Peru and Prasad, et al. [37] in India found a predominance of partial seizures with respective frequencies of $64.3 \%$ and $56.5 \%$. It is recognized in the literature that in NCC, seizures can be of all types (generalized or partial), but the generalized tonic-clonic seizures noted in the majority of studies [38]. 
Blood hyperosinophilia was present in 5 cases (38\%) in our series. It has an interest in the diagnostic orientation of NCC and is inconstant: variable during the acute phase of the disease, it may be absent in the advanced phase $[18,39]$.

Neuroimaging plays an important role in the diagnosis, allowing the visualization of the different parasitic stages within or outside the cerebral parenchyma. Its main limitations in public health are their availability and their cost in endemic countries [40]. Neuroimaging varies with the evolutionary stage of the parasite and the response of the host. They make it possible to specify various locations, number and size and stage of lesions [41]. In our study, lesions were much more intra-parenchymal than extra-parenchymal. The parietal location was the most found (92.3\%). Intraparenchymal NCC (the most common clinical form) occurs when the cyst is located in the brain parenchyma [42]. Several studies have found the predominance of parenchymal cysticercus lesions $[19,43]$. Shrestha, et al. [20] found parietal location $(40 \%)$ followed by frontal location (18.36\%). In Peru, Nash, et al. [44] found $78 \%$ of the lesions in the parietal lobe.

We found several types of lesions in our study with a predominance of calcified lesions (69.2\%). Several studies have reported calcifications as predominant lesions $[28,41,45,46]$. We found a minimum number of 10 lesions in $46.2 \%$ of the patients. In Tanzania, Blocher, et al. [45] found a minimum of 9 lesions in $45 \%$ of the patients. Relative to the number of active stages, $76.9 \%$ of the patients had lesions of a single active stage. In contrast, $23.1 \%$ of the patients had lesions of several stages. Kabeya, et al. [19] reported in their study that $72 \%$ of the patients had lesions of a single evolutionary stage. Shretha, et al. [20] also found $89.8 \%$ of lesions of a single stage. Nash, et al. [44] found that no patient had more than one evolutionary stage. In our patients, almost a quarter had lesions of two or more life stages. The association of lesions of different evolutionary stages has been described by several authors $[24,41,45]$. The association of lesions of several stages signs several successive infestations [41].

The EEG features of epilepsy associated with cysticercosis are rarely described in the literature and do not indicate any specificity [47]. In our study, we did not objectify EEG abnormalities in most patients. In Burundi, Diagana, et al. [48] found $48 \%$ of normal signals. The EEG is not a good diagnostic tool for NCC; it would be normal in $60 \%$ of the cases, apart from the acute forms in which it is always abnormal. This is an insensitive and non-specific examination in this case. The abnormal signals are variable and do not always correspond to the symptomatology. However, it is an important element during the discussion and is used in conjunction with clinical examination and biological investigations. Only neuroimaging can then provide certainty about the etiology of seizures by showing the nature and location of lesions [49].

The antiparasitic drug used in our study was albendazole and AEDs were phenobarbital, carbamazepine, sodium valproate and levetiracetam. Some of our patients were put on corticosteroids such as prednisone. This treatment was prescribed with good outcomes (total absence of symptoms in the course of evolution). The choice of an antiepileptic depends on the type of seizures. In many countries where NCC is endemic, AEDs (phenobarbital, phenytoin and sometimes carbamazepine) are relatively accessible. A single first-line treatment using one of the three available AEDs generally allows adequate seizure control in people with NCC although the effect has only been demonstrated with phenobarbital and carbamazepine [42]. The NCC treatment regimen includes symptomatic treatment with AEDs and analgesics and antiparasitic treatment. In most cases, corticosteroid therapy must be added [41]. Preventive measures are also important for the control and possibly eradication of NCC. Consequently, the treatment must be adapted to each case [50].

\section{Conclusion}

This study is a useful starting point from which health programs and health workers can work to improve the diagnosis and quality of epilepsy-NCC association management in our community. Early diagnosis and treatment of parasitic infestations are essential for the proper management of patients. Any patient presenting with acute onset of afebrile seizure should be screened for NCC provided other common infective and metabolic causes are ruled out. CT scan is the valuable diagnostic tool to support our diagnosis. Extensive studies are useful to better understand the epidemiology of epilepsy-NCC association in Lubumbashi city.

\section{Data availability}

The datasheet used to support the findings of this study is available from the corresponding author upon request.

\section{References}

1. Medina MT, De Giorgio CM. Introduction to neurocysticercosis: a worldwilde epidemic. Neurosurg Focus. 2002; 12: 1.

2. Lescano AG, Garcia HH, Gilman RH, Gavidia CM, Tsang VCW, et al. Taenia solium cysticercosis hotspots surrounding tapeworm carriers: clustering on human seroprevalence but not on seizures. PLoS Negl Trop Dis. 2009; 3: e371.

PubMed: https://pubmed.ncbi.nlm.nih.gov/19172178/

3. Garcia HH, Nash TE, Del Brutto $\mathrm{OH}$. Clinical symptoms, diagnosis, and treatment of neurocysticercosis. Lancet Neurol. 2014; 13: 1202-1215. PubMed: https://pubmed.ncbi.nlm.nih.gov/25453460/

4. Sotelo J, Guerrero V, Rubio F. Neurocysticercosis: a new classification base on active and inactive forms. A study of 753 cases. Arch Intern Med. 1985; 145: 442-445.

PubMed: https://pubmed.ncbi.nlm.nih.gov/3977513/

5. Carabin H, Ndimubanzi PC, Budke CM, et al. Clinical manifestations associated with neurocysticercosis: a systematic review. PLoS Neglected Trop Dis. 2011; 5: e1152.

PubMed: https://pubmed.ncbi.nlm.nih.gov/21629722/

6. Scharf D. Neurocysticercosis. Two hundred thirty-eight cases from a California hospital. Arch Neurol. 1998; 45: 777-780. 
7. Bugeme $M$, Mukuku $O$. Neurocysticercose révélée par une épilepsie réfractaire: à propos d'une observation. Pan African Med J. 2015; 20: 104 PubMed: https://www.ncbi.nlm.nih.gov/pmc/articles/PMC4458307/

8. Newton CR, Garcia HH. Epilepsy in poor regions of the world. The Lancet. 2012; 380: 1193-1201.

PubMed:https://pubmed.ncbi.nlm.nih.gov/23021288/

9. Montano SM, Villaran MV, Ylquimiche L, et al. Neurocysticercosis: association between seizures, serology, and brain CT in rural Peru. Neurology. 2005; 65: 229-233.

PubMed: https://pubmed.ncbi.nlm.nih.gov/16043791/

10. Carter JA, Neville BG, White $S$, et al. Increased prevalence of epilepsy associated with severe falciparum malaria in children. Epilepsia. 2004; 45: 978-981.

PubMed: https://pubmed.ncbi.nlm.nih.gov/15270766/

11. Annegers JF, Hauser WA, Beghi E, Nicolosi A, Kurland LT. The risk of unprovoked seizures after encephalitis and meningitis. Neurology. 1988; 38: 1407-1410.

PubMed: https://pubmed.ncbi.nlm.nih.gov/3412588/

12. Del Brutto $\mathrm{OH}$, Santibanez R, Idrovo L, et al. Epilepsy and neurocysticercosis in Atahualpa: a door-to-door survey in rural coastal Ecuador. Epilepsia. 2005; 46: 583-587.

PubMed: https://pubmed.ncbi.nlm.nih.gov/15816956/

13. Mukuku O, Nawej P, Bugeme M, Nduu F, Mawaw PM, et al. Epidemiology of Epilepsy in Lubumbashi, Democratic Republic of Congo. Neurology Research International. 2020; 2020.

14. Del Brutto OH, Arroyo G, Del Brutto VJ, Zambrano M, García HH. On the relationship between calcified neurocysticercosis and epilepsy in an endemic village: A large scale, computed tomography-based population study in rural Ecuador. Epilepsia. 2017; 58: 1955-1961. PubMed: https://pubmed.ncbi.nlm.nih.gov/28850668/

15. Winkler AS, Blocher J, Auer H, Gotwald T, Matuja W, Schmutzhard E. Epilepsy and neurocysticercosis in rural Tanzania-an imaging study. Epilepsia. 2009; 50: 987-993.

PubMed: https://pubmed.ncbi.nlm.nih.gov/19054402/

16. Del Brutto OH, Nash TE, White AC, Rajshekhar V, Wilkins PP, et al. Revised diagnostic criteria for neurocysticercosis. J Neurol Sci. 2017; 372: 202-210.

PubMed: https://pubmed.ncbi.nlm.nih.gov/28017213/

17. Fisher RS, Acevedo C, Arzimanoglou A, Bogacz A, Cross JH, et al. Définition clinique pratique de l'épilepsie. Epilepsia. 2014; 55: 475-482. PubMed: https://pubmed.ncbi.nlm.nih.gov/24730690/

18. Duchene M, Benoudiba F, Iffenecker C, Hadj-Rabia M, Caldas JGMP, Doyon D. La neurocysticercose. J Radiol. 1999; 80: 1623-1627. PubMed: https://www.ncbi.nlm.nih.gov/pmc/articles/PMC4458307/

19. Kabeya-Kabenkama J, Tshikwela M L, Mpoyo-Mukendi W, SaidMutena E. Neurocysticercose à Kinshasa: imagerie et clinique à propos de 11 cas. J Radiol. 2007; 88: 1443.

PubMed: https://www.ncbi.nlm.nih.gov/pmc/articles/PMC4458307/

20. Shrestha B, Mainali P, Sayami S, Shrestha O K. Clinico-radiological aspects of neurocysticercosis in pediatric population in a tertiary hospital. J Nepal Med Assoc. 2013; 52.

21. Miranda LP, Zambrana MM. Frequency of epilepsy in patients with neurocysticercosis, in the service neurology and neurosurgery motherchild hospital. J Neurol Sci. 2015; 357: e456.

PubMed: https://www.ncbi.nlm.nih.gov/pmc/articles/PMC1736787/

22. Garcia HH, Gilman R, Martinez M, Tsang VC, Pilcher JB, et al. Cysticercosis as a major cause of epilepsy in Peru. The Cysticercosis Working Group in Peru (CWG). Lancet. 1993; 341:197-200. PubMed: https://www.ncbi.nlm.nih.gov/pmc/articles/PMC2917763/

23. Nsengiyumva G, Druet-Cabanac M, Ramanankandrasana B, Bouteille $B, N s i z a b i r a ~ L$, et al. Cysticercosis as a major risk factor for epilepsy in Burundi, East Africa. Epilepsia. 2003; 44: 950-955.

PubMed: https://pubmed.ncbi.nlm.nih.gov/12823579/
24. Sonhaye L, Tchaou M, Amadou A, Assih K, Kolou B, et al. Valeur diagnostique de la tomodensitométrie dans la cysticercose cérébrale à Lomé. Pan African Med J. 2015; 20: 67.

PubMed: https://www.ncbi.nlm.nih.gov/pmc/articles/PMC4450042/

25. Garcia HH, Pretell EJ, Gilmann RH, Martinez SM, Moulton LH, et al. A trial of antiparasitic treatment to reduce the rate of seizures due to cerebral cysticercosis. N Engl J Med. 2004; 350: 249-258. PubMed: https://pubmed.ncbi.nlm.nih.gov/14724304/

26. Fleury A, Dessein A, Dumas M, Preux PM, Tapia G, et al. Symptomatic human neurocysticercosis: age, sex and exposure factors relating with disease heterogeneity. J Neurology. 2004; 251: 830-837. PubMed: https://pubmed.ncbi.nlm.nih.gov/15258785/

27. Mwang'onde BJ, Chacha MJ, Nkwengulila G. The status and health burden of neurocysticercosis in Mbulu district, northern Tanzania. BMC Res Notes. 2018; 11: 890.

PubMed: https://pubmed.ncbi.nlm.nih.gov/30545404/

28. Millogo A, Nitiéma $P$, Carabin $H$, Boncoeur-Martel MP, Rajshekhar V, et al. Prevalence of neurocysticercosis among people with epilepsy in rural areas of Burkina Faso. Epilepsia. 2012; 53: 2194-2202. PubMed: https://pubmed.ncbi.nlm.nih.gov/23148555/

29. Zafindraibe NJ, Ralalarinivo J, Rakotoniaina Al, Maeder MN, Andrianarivelo $M R$, et al. Séroprévalence de la cysticercose et facteurs de risque associés chez un groupe de patients vus au Centre Hospitalier Régional de Référence d'Antsirabe, Madagascar. Pan African Med J. 2017; 28.

PubMed: https://www.ncbi.nlm.nih.gov/pmc/articles/PMC5989193/

30. Andriantsimahavandy A, Ravaoalimalala VE, Rajaonarison $P$, Ravoniarimbinina $\mathrm{P}$, Rakotondrazaka $\mathrm{M}$, et al. Situation épidémiologique actuelle de la cysticercose à Madagascar. Arch Inst Pasteur de Madagascar. 2003; 69: 46-45.

31. Ndiaye A, Niass MD, Diouf M, Faye N. Profil épidémiologique des parasitoses digestives au centre d'analyse du centre hospitalier Abass Ndao de 2011 à 2012. Open Sci Repos Med. 2014. e23050482.

32. Fain A, Limbos P, Van Ros G, De Mulder P, Herin A. Présence du cestode raillietina celebrensis chez un enfant originaire de Tahiti. Ann. Soc. Belge Méd Trop. 1977; 57: 137-142.

33. Paugam A. Parasitoses et atteinte neurologique. Revue Francophone des Laboratoires, 2008; 399: 41-53.

34. Sil A, Das K, Das NK, Chakraborty D, Mazumdar G, et al. Use of antiepileptic drugs in a tertiary care hospital of Eastern India with emphasis on epilepsy due to neurocysticercosis. Indian J Pharmacol. 2012; 44: 106-110.

PubMed: https://pubmed.ncbi.nlm.nih.gov/22345881/

35. Cruz ME, Schantz PM, Cruz I, Espinosa P, Preux PM, et al. Epilepsy and neurocysticercosis in an Andean community. Int $\mathrm{J}$ Epidemiol. 1999; 28: 799-803.

PubMed: https://pubmed.ncbi.nlm.nih.gov/10480714/

36. Moyano LM, Saito M, Montano SM, Gonzalvez G, Olaya S, et al. Neurocysticercosis as a cause of epilepsy and seizures in two community-based studies in a cysticercosis-endemic region in Peru. PLoS Neglected Tropical Diseases. 2014; 8: e2692.

PubMed: https://pubmed.ncbi.nlm.nih.gov/24551255/

37. Prasad KN, Prasad A, Gupta RK, Nath K, Pradhan S, et al. Neurocysticercosis in patients with active epilepsy from the pig farming community of Lucknow district, north India. Transactions of the Royal Society of Tropical Medicine and Hygiene. 2009; 103: 144-150. PubMed: https://pubmed.ncbi.nlm.nih.gov/18804830/

38. Sciutto E, Fragoso G, Fleury A, Laclette JP, Sotelo J, AlujaA, et al. Taeniasolium disease in humans and pigs: an ancient parasitosis disease rooted in developing countries and emerging as a major health problem of global dimensions. Microbes Infect. 2000; 2: 1875-1890. PubMed: https://pubmed.ncbi.nlm.nih.gov/11165932

39. Rajaonarison P, RalambosonS, Andriamamonjy C, Ramanampamonjy R, 
Ramanantoanina $\mathrm{CE}$, et al. Diagnostic de la neurocysticercose: à propos d'un cas. Archives de l'Institut Pasteur de Madagascar. 2001; 67: 53-56.

40. Almeida CR, Ojopi EP, Nunes CM, Machado LR, Takayanagui OM, et al. Taenia solium DNA is present in the cerebrospinal fluid of neurocysticercosis patients and can be used for diagnosis. European archives of psychiatry and clinical neuroscience. 2006; 256: 307-310. PubMed: https://pubmed.ncbi.nlm.nih.gov/16816897/

41. Ky H, Van Chap NG. Aspects radiocliniques de la cysticercose cérébrale et musculaire: A propos de 20 observations. J Neuroradiol. 2000; 27: 264-266.

42. Millogo A. Neurocysticercose et épilepsie. Revue Neurologique. 2015; 171: A203-A204.

43. Xiao A, Zeng $H$, Xiao J, Zhang X, You C. Imaging Features of Neurocysticercosis: Analysis of 57 Consecutive Patients. Turk Neurosurg. 2017; 27: 386-394.

PubMed: https://pubmed.ncbi.nlm.nih.gov/27593775/

44. Nash TE, Pretell EJ, Lescano AG, Bustos JA, Gilman RH, et al. Cysticercosis Working Group in Peru. Perilesional brain oedema and seizure activity in patients with calcified neurocysticercosis: a prospective cohort and nested case-control study. The Lancet. Neurology. 2008; 7: 1099-1105.

PubMed: https://pubmed.ncbi.nlm.nih.gov/18986841/
45. Blocher J, Schmutzhard E, Wilkins PP, Gupton PN, Schaffert M, et al. A cross-sectional study of people with epilepsy and neurocysticercosis in Tanzania: clinical characteristics and diagnostic approaches. PLoS neglected tropical diseases. 2011; 5: e1185.

PubMed: https://www.ncbi.nlm.nih.gov/pmc/articles/PMC3110162/

46. Webb CM, White AC. Update on the diagnosis and management of neurocysticercosis. Current infectious disease reports. 2016; 18: 44. PubMed: https://pubmed.ncbi.nlm.nih.gov/27787774/

47. Preux PM, Melaku Z, Druet-Cabanac M, Avode GD, Grunitzky EK, et al. Cysticercosis and neurocysticercosis in Africa: curent status. Neurol Infect Epidemiol. 1996; 1: 63-68.

48. Diagana M, Nsengiyumva G, Tuillas M, Druet-Cabanac M, Bouteille B, et al. Électroencéphalogrammes réalisés chez 250 patients épileptiques dans une zone d'endémie cysticerquienne au Burundi. Neurophysiologie Clinique/Clinical Neurophysiology. 2005; 35: 1-10.

49. Lopez-Hernandez A, Garaizar C. Manifestations of infantile cerebral cysticercosis. In: Palacios E, Rodriguez-Carbajal J, Tavares JM, editors. Cysticercosis of central nervous system. Spingfield, IL: Charles C Thomas. 1983; 69-83.

50. Fogang YF, Savadogo AA, Camara M, Toffa DH, Basse A, et al. Managing neurocysticercosis: challenges and solutions. International J General Med. 2015; 8: 333-344.

PubMed: https://pubmed.ncbi.nlm.nih.gov/26527895/ 